\title{
Assessing the Biofilm Formation Capacity of the Wine Spoilage Yeast Brettanomyces bruxellensis through FTIR Spectroscopy
}

\author{
Maria Dimopoulou, Vasiliki Kefalloniti, Panagiotis Tsakanikas (D), Seraphim Papanikolaou \\ and George-John E. Nychas *(D)
}

check for

updates

Citation: Dimopoulou, M.; Kefalloniti, V.; Tsakanikas, P.; Papanikolaou, S.; Nychas, G.-J.E. Assessing the Biofilm Formation Capacity of the Wine Spoilage Yeast Brettanomyces bruxellensis through FTIR Spectroscopy. Microorganisms 2021, 9, 587. https://doi.org/ 10.3390/microorganisms 9030587

Academic Editors: Giuseppe Comi and Franca Rossi

Received: 14 February 2021

Accepted: 11 March 2021

Published: 12 March 2021

Publisher's Note: MDPI stays neutral with regard to jurisdictional claims in published maps and institutional affiliations.

Copyright: (c) 2021 by the authors. Licensee MDPI, Basel, Switzerland. This article is an open access article distributed under the terms and conditions of the Creative Commons Attribution (CC BY) license (https:/ / creativecommons.org/licenses/by/ $4.0 /)$.
Laboratory of Microbiology and Biotechnology of Foods, Department of Food Science and Human Nutrition, School of Food and Nutritional Sciences, Agricultural University of Athens, Iera Odos 75, 11855 Athens, Greece; maroula.dimo@hotmail.com (M.D.); kefalloniti.v@gmail.com (V.K.); p.tsakanikas@aua.gr (P.T.); spapanik@aua.gr (S.P.)

* Correspondence: gjn@aua.gr; Tel./Fax: +30-210-5294693

Abstract: Brettanomyces bruxellensis is a wine spoilage yeast known to colonize and persist in production cellars. However, knowledge on the biofilm formation capacity of B. bruxellensis remains limited. The present study investigated the biofilm formation of 11 B. bruxellensis strains on stainless steel coupons after $3 \mathrm{~h}$ of incubation in an aqueous solution. FTIR analysis was performed for both planktonic and attached cells, while comparison of the obtained spectra revealed chemical groups implicated in the biofilm formation process. The increased region corresponding to polysaccharides and lipids clearly discriminated the obtained spectra, while the absorption peaks at the specific wavenumbers possibly reveal the presence of $\beta$-glucans, mannas and ergosterol. Unsupervised clustering and supervised classification were employed to identify the important wavenumbers of the whole spectra. The fact that all the metabolic fingerprints of the attached versus the planktonic cells were similar within the same cell phenotype class and different between the two phenotypes, implies a clear separation of the cell phenotype; supported by the results of the developed classification model. This study represents the first to succeed at applying a non-invasive technique to reveal the metabolic fingerprint implicated in the biofilm formation capacity of B. bruxellensis, underlying the homogenous mechanism within the yeast species.

Keywords: Brettanomyces bruxellensis; biofilm formation; FTIR analysis; machine learning; classification; wine spoilage

\section{Introduction}

Brettanomyces bruxellensis is non-conventional wine yeast, with remarkable spoilage potential. The spoilage effect is due to the high level of production of undesirable volatile phenols through the metabolism of the hydroxycinnamic acids in grapes, which have a detrimental and irreversible effect on the wine's aroma [1-5]. Additionally, the capacity of the species to enter under oenological conditions into a viable but not cultivable (VBNC) state shows that the frequently used culture dependent methods could create a false estimation of the yeast population, complicating the detection of yeast in production facilities [6,7]. The fact that B. bruxellensis exhibits an elevated ability to invade wine cellars and contaminate winery equipment, represents an area of increasing concern for the wine industry [8,9]. The occurrence of B. bruxellensis in winemaking equipment highlights the colonization and the biofilm formation capacity of the species in the winemaking environment, and consequently, demonstrates the persistence of the yeast in the cellar from one year to the next $[8,10]$.

Biofilms are highly structured multicellular aggregates that are able to adhere to and grow on biotic and abiotic surfaces [11-13]. This complex structure is mainly composed of cell-produced extracellular polymeric substances (EPS), which are essential for biofilm formation. EPS comprise a wide variety of polysaccharides, proteins, glycoproteins, as 
well as glycolipids and extracellular DNA (e-DNA) [14]. So far, the methods used for the identification of the EPS are quite invasive and the extraction protocols usually target specific molecules of interest and not the whole matrix [12].

Fourier transform infrared (FTIR) spectroscopy is a powerful, fast and non-invasive technique for generating direct information about the molecular and chemical composition of the analyzed sample, based on the absorption of infrared radiation [15]. The technique is based on the vibration of atoms when the IR radiation passes through the sample, which generates a vibrational spectra specific to each compound [13]. The method is widely applied to discriminate biological samples due to the fact that different cell components produce different absorption profiles [16]. More precisely, FTIR has been used for the classification and identification of microorganisms at the species and strain levels [17,18]. Interestingly, the method has proven to be capable of identifying species of clinical samples for diagnostic reasons or for epidemiological surveillance [19]. In the food industry, the metabolic fingerprint obtained from the FTIR spectra can be used for rapid food identification, detection and prediction of microbial spoilage [20-23]. Additionally, the FTIR spectra analysis can record the biochemical compounds excreted by the microorganisms, such as those implicated in the EPS biofilm matrix. For instance, FTIR was recently successfully applied to characterize the chemical composition of the biofilm matrix implicated in dental plaque formation by streptococci species [24]. Respectively, by the same reasoning, FTIR can also be applied to predict the microbial mode of life in planktonic or embedded growth.

The aim of the present study was to deepen our knowledge on the biofilm formation capacity of B. bruxellensis on stainless steel surfaces by applying FTIR spectroscopy. For this reason, the main parts of the study were to (i) investigate the adhesion capacity of eleven strains of the species, (ii) compare the metabolic fingerprint of the attached vs. planktonic cells, (iii) reveal and discuss the compounds of interest implicated in the biofilm formation capacity of the species associated with wine spoilage.

\section{Materials and Methods}

\subsection{Yeast Strains and Growth Condition}

B. bruxellensis strains previously isolated from oenological materials [25] were kindly provided from the ARS Culture Collection (NRRL) and Institute of Oenology of Bordeaux (IOEB) collection, as well as from the collection of the Department of Food Science and Technology of Aristotle University of Thessaloniki. The 11 strains belonged to six different genetic groups based on the analysis of 12 microsatellites markers especially developed for the species [26].

\subsection{Biofilm Formation on Stainless Steel Coupons}

The 11 strains of B. bruxellensis were tested for their biofilm formation capacity on stainless steel coupons. Microorganisms were stored at $-80^{\circ} \mathrm{C}$ in vials with glycerol (30\%) and were activated by adding $200 \mu \mathrm{L}$ to $10 \mathrm{~mL}$ Yeast Peptone Dextrose (YPD) medium at $28^{\circ} \mathrm{C}$ for $48 \mathrm{~h}$. Then, for the working cultures, a $100 \mu \mathrm{L}$ suspension of the activated cells was inoculated in $10 \mathrm{~mL}$ of YPD and left for $72 \mathrm{~h}$ until reaching the late exponential phase.

Cells for the working cultures were rinsed twice $\left(4000 \times \mathrm{g}, 4^{\circ} \mathrm{C}, 10 \mathrm{~min}\right)$ with sterile Ringer solution (tablets Merck KGaA, Darmstadt, Germany) and re-suspended in Ringer solution in order to obtain an $\mathrm{OD}_{600 \mathrm{~nm}}=1$. A total of $0.5 \mathrm{~mL}$ of the cell suspension was added to a test tube containing $4.5 \mathrm{~mL}$ of Ringer solution and one coupon of stainless steel $\left(3 \times 0.8 \times 0.1 \mathrm{~cm}\right.$ type AISi-304), reaching an inoculation rate of $10^{7} \mathrm{cfu} / \mathrm{mL}$. A $5 \mathrm{~mL}$ amount of the final cell suspension in Ringer solution completely covered the coupon surface and was left at $25^{\circ} \mathrm{C}$ for $3 \mathrm{~h}$. After the incubation period, $1 \mathrm{~mL}$ of the culture was used to estimate the population of planktonic cells (10-fold serial dilutions on YPD agar plates) while the coupon was carefully removed with sterile forceps to a new tube and washed on both sides with Ringer solution in order to remove all the loosely attached cells. After the washing step, the coupon was transferred to a new falcon tube containing $6 \mathrm{~mL}$ of Ringer solution and 10 sterile glass beads $(3 \mathrm{~mm})$ covered with silicon to perform 
the bead vortex method. Each falcon tube containing the coupon was vigorously swirled (vortex) for $2 \mathrm{~min}$. After vortexing, $1 \mathrm{~mL}$ of suspension was used to estimate the attached cultivable cell population (10-fold serial dilutions on YPD agar plates). Each experiment was performed in triplicate and repeated independently two times.

\subsection{Fourier Transform Infrared Spectroscopy}

The infrared spectra of the cell suspension samples were recorded by a ZnSe 45o HATR (Horizontal Attenuated Total Reflectance) crystal (PIKE Technologies, Madison, WI, USA) and by a FTIR-6200 JASCO spectrometer (Jasco Corp., Tokyo, Japan). Spectra ManagerTM Code of Federal Regulations software v. 2 (Jasco Corp.) was used to collect the obtained spectra (wavenumber range of 4000 to $400 \mathrm{~cm}^{-1}$ ).

After $3 \mathrm{~h}$ of incubation in contact with the coupon surface, $1 \mathrm{~mL}$ of culture of the 11 B. bruxellensis strains was retrieved and transferred to the crystal plate in order to obtain the FTIR spectra of the planktonic cells. Then, after performing the bead vortex method for dispatching the attached cells from the formed biofilm on the coupon surface, $1 \mathrm{~mL}$ of suspension was transferred to the crystal plate to obtain the attached cells spectra, respectively. The process is illustrated in Figure 1. Prior to the first sample measurement, the reference spectra of the crystal were obtained and this process was repeated after every five sample measurements. Between measurements, the crystal was cleaned with distilled water and acetone, while it was left to dry completely until the next sample addition.

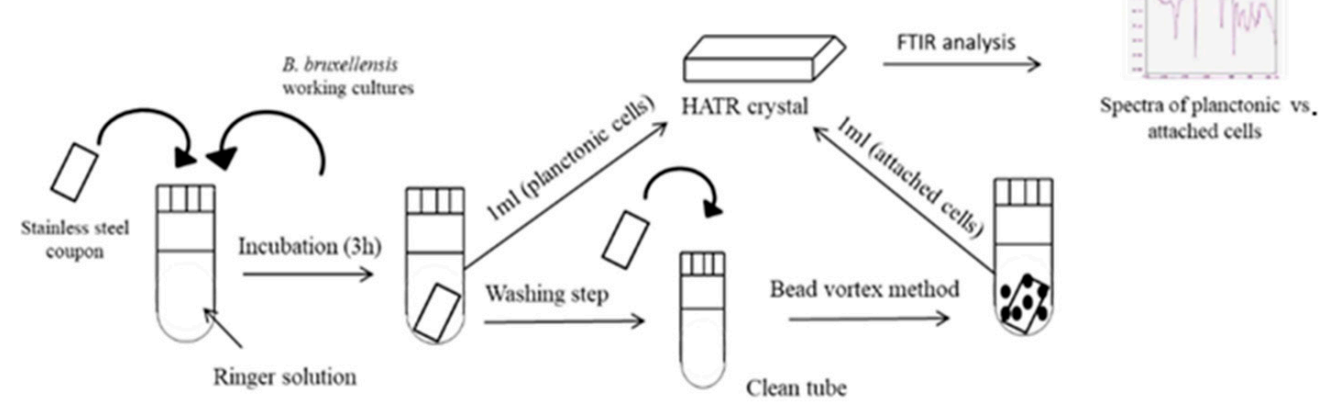

Figure 1. Schematic representation of the main steps implicated in samples preparation for the FTIR analysis. HATR: Horizontal Attenuated Total Reflectance

\subsection{FTIR Spectra Data Analysis}

Herein, a detailed description is provided of the analysis pipeline and the corresponding justification (please refer to Figure 2). The data processing and analysis pipeline consists of data pre-processing and normalization, followed by the extra-tree method [27] (standing for extremely randomized trees), employed specifically for supervised dimensionality reduction on the basis of informative, important wavenumber selection. After the wave numbers were selected and the problem was limited to a small space (fewer features), we followed two different approaches in order to essentially reach the same target. Concerning the first approach, we employed unsupervised clustering of the data using principal component analysis (PCA) [28] and Gaussian mixture modeling [29] in order to identify if the two clusters of planktonic and adhered samples appeared as the "natural" clusters of the data. At the second approach we follow a classification strategy where the selected wavenumbers have been used as inputs to an SVM [30] classifier in order to be trained and used as a model for sample prediction, decision making. 


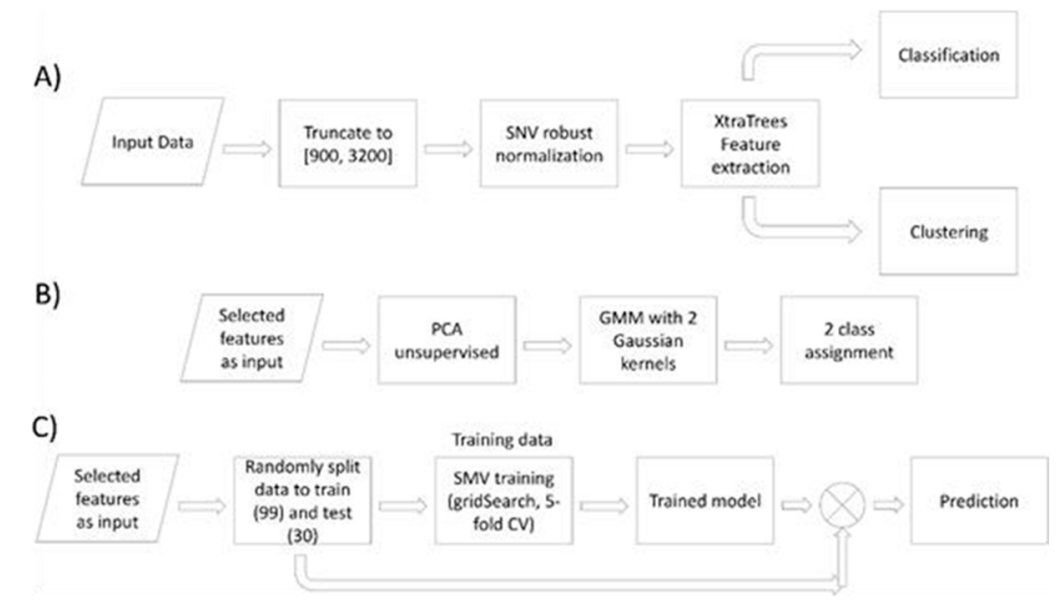

Figure 2. Overview of the data analysis and exploration. (A) Data manipulation steps towards classification and clustering. (B) Clustering workflow, natural clusters identification. (C) Classification pipeline, training and validation. SNV: standard normal variate; PCA: principal component analysis.

As shown in Figure 2, the first data manipulation process is to truncate the noisy areas at the start of the spectra and the area above $\sim 3100 \mathrm{~cm}^{-1}$, corresponding to the absorption of water (any information under this peak is hidden and cannot be extracted) prior to normalization (refer to Supplement Material Figure S1A). Thus, we have the range $\sim 880-3100 \mathrm{~cm}^{-1}$. Next in the workflow, and in order to enhance the quality of the data while also reducing the correlated information across the different wavenumbers and eliminate the inherent multiplicative noise, the robust normal variate [31] (RNV) modelwhich the the robust version of the standard normal variate [32] (SNV) model—is employed so as to ensure improved downstream analysis (please refer to Supplementary Materials Figure S1B). Specifically, the RNV is given by:

$$
\operatorname{Sisnv}=\operatorname{si}-\operatorname{median}(S) / \operatorname{mad}(S)
$$

where $S$ is the ensemble of all spectra, and si and sisnv are the ith and the corresponding normalized spectra, respectively. median absolute deviation [33] (mad) is a robust measure of the variability of a univariate sample of quantitative data $\mathrm{s} 1, \mathrm{~s} 2, \ldots$, sn computed as:

$$
\text { mad }=\text { median }(s i)-\operatorname{median}(S)
$$

As the next step, dimensionality reduction via feature selection was performed. For this, our method of choice was the extra-trees method, which we used in order to identify the most important and informative wavenumbers for classifying the planktonic vs. biofilm state/phenotype. This step is critical since in this study we have 116 samples and each sample-after the aforementioned pre-processing steps-counts for 2300 features. Thus, by limiting the number of variables, we were able to avoid overfitting, downgrading to a lower dimension space, while simplifying our problem both for clustering and classification. First, we split the data (129 samples, where 63 were from biofilm and 66 were from planktonic forms) randomly into training (99) and test (30; 16 planktonic and 14 biofilm) groups. The extra-trees was trained with 50 trees in the forest, five-fold cross validation and the function to measure the quality of a split was "gini" for the Gini impurity. Gini impurity is a measure of how often a randomly chosen element from the set would be incorrectly labelled if it was randomly labelled according to the distribution of labels in the subset. Random forest analysis has been previously used in food analysis [23,34-36]. Herein, we turn to extra-trees, where the main objective is to further randomize tree building in the context of numerical input features, where the choice of the optimal cut-point is responsible for a large proportion of the variance of the induced tree. In comparison to random forests, the extra-trees method drops the idea of using bootstrap copies of the learning sample 
and instead of trying to find an optimal cut-point for each one of the $\mathrm{K}$ randomly chosen features at each node, it selects a cut-point at random. In the productive context of having many problems characterized by a large number of numerical features varying more or less continuously, as we have here, the extra-trees method can lead to increased accuracy due to its smoothing, while it simultaneously has a lower computation cost as it does not rely on the determination of optimal cut-points as is the case in standard trees and in random forests. Furthermore, leaving the bootstrapping idea can lead to advantages in terms of bias, whereas the cut-point randomization method often results in an excellent variance reduction effect [27]. Finally, from a functional point of view, the extra-trees method produces piece-wise multilinear approximations, rather than the piece-wise constant ones of the random forest method. Therefore, for all of these reasons, we believe that the adopted approach presented herein will provide us with robust features for efficient classification and clustering purposes.

Under the scope of the explanatory data analysis via unsupervised clustering, we used the data (129 FTIR spectra samples) with a reduced number of features, as discussed previously. As the next step and in order to visualize the data, we further reduced the dimensionality by principal component analysis (PCA). The first two principal components accounted for $99.4 \%$ of the total variance of the data and we kept only these first two components. On the two-dimensional space of PC1 and PC2, we applied Gaussian mixture modeling with two clusters, as this is the number of known states of B. bruxellensis.

Concerning the classification analysis pipeline, SVM-based modeling was employed with the use of the reduced dimensionality data and the output of the extra-trees method. Support vector machines (SVMs) are models that are created in a supervised manner and are used for classification and regression analyses [37]. SVMs are a well suited classification technique when the training data consist of large number of variables in relation to the number of observations. In our case, the input matrix $X$ contains 99 normalized FTIR training samples with 45 variables/wavenumbers each, while the $\mathrm{Y}$ matrix is a single column matrix consisting of the class (coded as a number, 0 and 1) for each corresponding sample state, i.e., attached or planktonic. A five-fold cross-validation method was used, with shuffling of the training set, and it was then split into five subsets (folds). A grid search [38] was also applied for determining the optimum parameters for the SVM model. A grid search is an exhaustive search through a manually specified subset of the parameter space, combined with cross validation, in an attempt to compute the ideal kernel and parameters for the SVM classification. Herein, the kernels tested were: linear, radial basis function (rbf) and polynomial, the search range for $C$ parameter was set as $(0.0001$, $0.001,0.01,0.1,1,10,100,1000)$, while the $\gamma$ parameter $(10-6,10-1)$ was in a logarithmic scale and the degree $=2,3,4$ and 5 . The outcomes for the hyper-parameters grid search resulted in choosing the linear kernel and $C=10$, as the optimal classifier parameters for our data. Afterwards, the SVM was trained using the resulting optimal kernel and corresponding parameters.

The whole workflow was implemented in python 3.7, employing the scikit-learn library $[38,39]$. All codes and data used herein are available upon request from the authors.

\subsection{Statistical Analysis}

Results are expressed as mean \pm standard deviation of the independent experiments and analysis of variance (ANOVA), followed by post hoc Tukey's test (HSD), was used for comparisons. A $p$-value $\leq 0.05$ was considered statistically significant.

\section{Results}

\subsection{Biofilm Formation Capacity of B. bruxellensis Strains on Stainless Steel Coupons}

Strain variability has often been observed for the studied species under the various phenotypic traits and for the particular case of biofilm formation $[7,8,37]$. In this study, 11 strains from different genetic groups were chosen based on previous studies that tested the population structure of approximately 1510 isolates of B. bruxellensis from 29 countries. 
Based on microsatellite analysis, the tested isolates were grouped into six main genetic groups, named by the reference strain of each group: strains AWRI1608 and GSP1516 (AWRI 1608-like), strains CBS 2499 and CBS 78 (2499-like), strains 33.1 and 33.3 (AWRI 1499-like), CBS5512 and CBS 6055 (CBS5512-like), strain UWOPS92.244.4 (L0308-like and L14165-like), and strains 15.12 and 45.3 (L 14165-like) [40,41].

The biofilm formation capacity of the 11 B. bruxellensis strains on a stainless steel surface in an aqueous solution was monitored in six independent biological replicates, with an incubation period of $3 \mathrm{~h}$. All the strains were inoculated at the same population level of $10^{7} \mathrm{cfu} / \mathrm{mL}$. Statistical comparisons separated the strains into three groups based on their adhesion capacity (Figure 3). The strain 33.3 presented the smallest attached cell population on the coupons $\left(\log _{10} 2.32 \pm 0.29 \mathrm{cfu} / \mathrm{cm}^{2}\right)$, reaching statistical significance. Seven strains belonged to the group that expressed an intermediate adhesion capacity, with an average population of attached cells of $\log _{10} 3.18 \pm 0.54 \mathrm{cfu} / \mathrm{cm}^{2}$. Three strains differed from the rest due to their high concentration of attached cells on the coupon surface: $33.1\left(\log _{10} 5.6 \pm 0.29 \mathrm{cfu} / \mathrm{cm}^{2}\right)$, CSB6055 $\left(\log _{10} 5.43 \pm 0.24 \mathrm{cfu} / \mathrm{cm}^{2}\right)$ and $15.12\left(\log _{10} 5.25 \pm 0.15 \mathrm{cfu} / \mathrm{cm}^{2}\right)$.

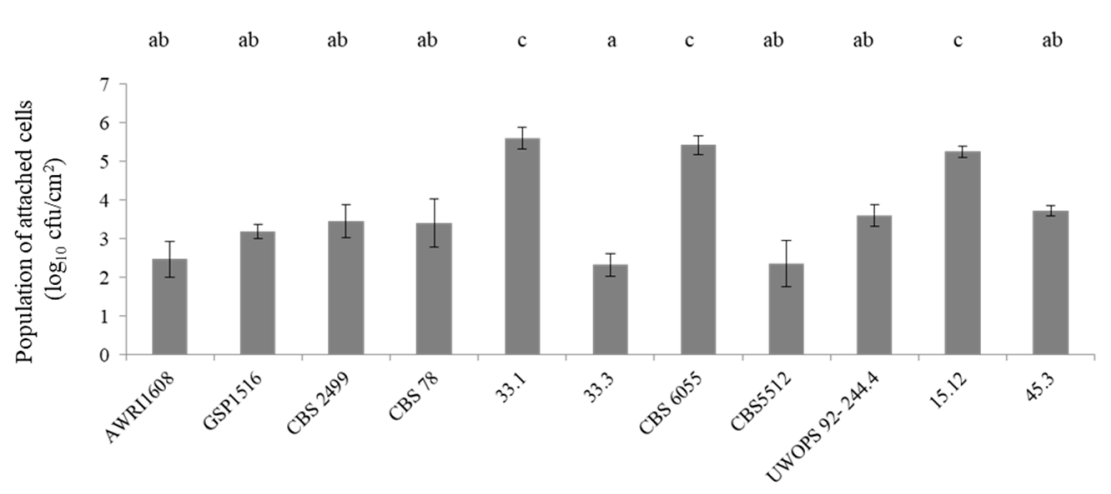

Figure 3. Mean population of attached cells ( \pm standard deviation, $n=6$ ) on stainless steel coupons of 11 strain s of B. bruxellensis in Ringer solution. Values with different superscript roman letter $(\mathrm{a}-\mathrm{c})$ in the same row are significantly different according to Tukey's post hoc test $(p<0.05)$.

\subsection{FTIR Spectra Analysis of Attached vs. Planktonic Cells of B. bruxellensis}

In this subsection, the results and findings of the two-way analysis of the FTIR spectra are presented, considering two states of the cells of B. bruxellensis for all 11 strains used herein. Following the first type of analysis, i.e., via unsupervised clustering (as discussed in the Material and Methods Section), we conclude that, given a set of measurements, we are able to identify two distinct populations forming two "natural" inherent classes that correspond to the distinction of attached cells vs. the planktonic cells. This result-also depicted in Figure 4 with the two mode mixture of Gaussians-is a very interesting outcome, showing that attached cells exhibit much less deviation among them even when the input spectra originate from different strains and cultures (11 strains and six independent cultures in our case). On the other hand, planktonic cells exhibit a greater level of variability in the PC space, but the two clusters are still easily separable along the PC1. This outcome could be used in the development of a model to cluster any new sample to one of these clusters, thus providing an efficient and reliable, non-invasive and direct decision-making approach, regardless of the specific strain and culture. The difference of the two cell states in the PC space can be explained if we consider the major difference between the two cell states, i.e., attached vs. planktonic cells. In the case of biofilm colony formation, this colony comprises a consortium of cells that stick to each other and to a surface [42]. These attached cells become embedded within a slimy extracellular matrix that is composed of extracellular polymeric substances (EPS), which are a polymeric conglomeration of extracellular polysaccharides, proteins, lipids and DNA $[43,44]$. Thus, these EPSs are expected to be less 
variant due to the differences among the strains and so this can explain the low variance of the Gaussian mode, representing the adhered/biofilm samples, as presented in Figure 4.

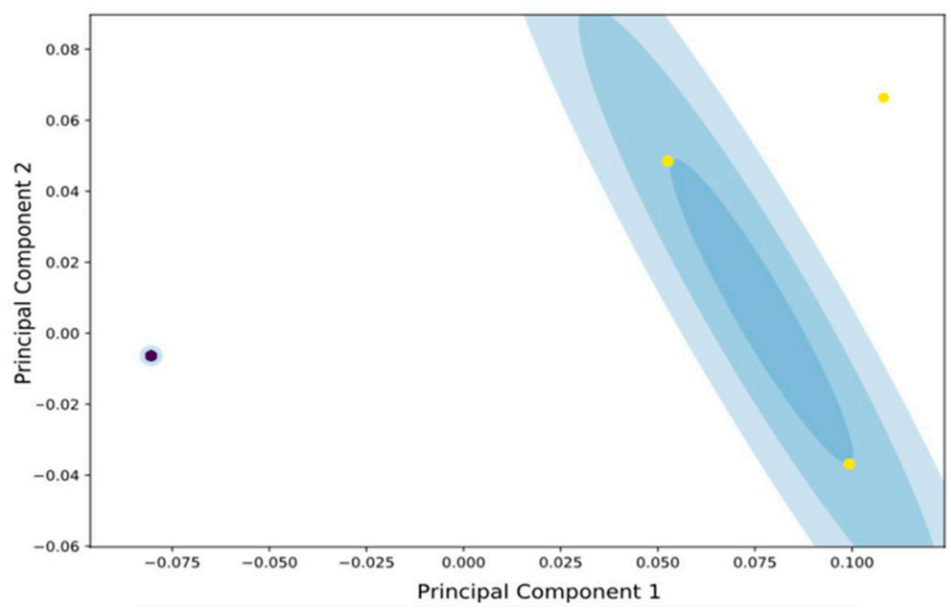

Figure 4. Gaussian mixture modeling of the samples of 11 B. bruxellensis strains in the 6 independent cultures considered. Yellow points represent the samples from planktonic cells, while blue represent attached cells. The blue shaded areas represent the Gaussian distributions corresponding to each cluster. For the planktonic cells, the distribution presents larger variance in comparison to the biofilm cell state.

\subsection{Chemical Compound Groups Discriminate Planktonic vs. Attached Cells}

Via the second FTIR spectra analysis method, we conducted a supervised classification procedure, as described in the Materials and Methods Section. Prior to unsupervised clustering and supervised classification, we employed extra-trees in order to identify the important/significant wavenumbers of the whole spectra. It turns out that only 45 wavenumbers (essentially corresponding to two major chemical classes, as discussed later on) are adequate for efficient and robust classification and clustering purposes. Therefore, using these 45 wave numbers (shown at Figure 5 as red vertical lines), we were able to build a classification model (SVM classifier with linear kernel, see Materials and Methods Section) that reached $100 \%$ accuracy in the five-fold cross validation training phase and also at the test/validation phase (Table 1), ensuring that no over-fitting occurred.

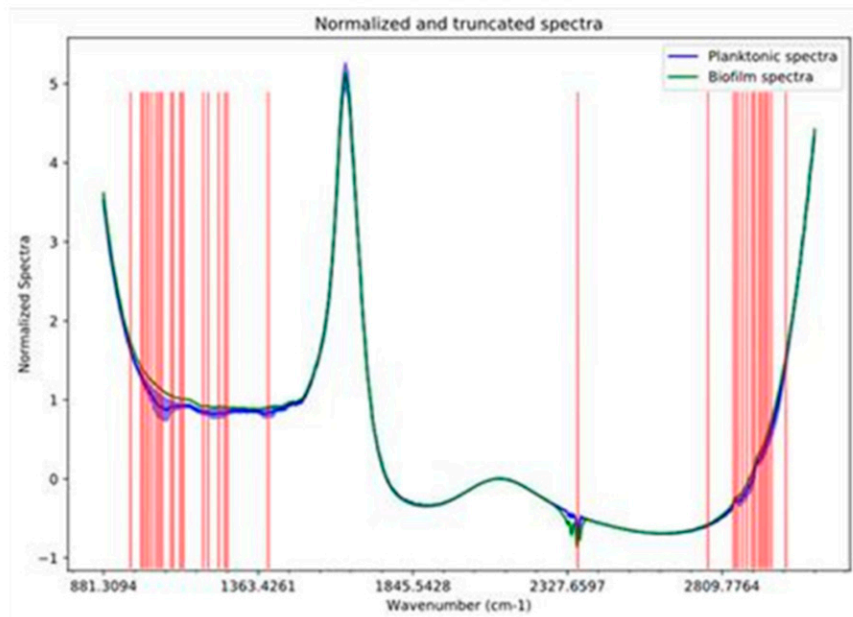

Figure 5. Fourier-transform infrared spectroscopy of attached and planktonic cells supernatant of 11 strains and 6 independent cultures of B. bruxellensis. Vertical red lines indicate the important and selected wavenumbers. 
Table 1. Confusion matrix of the test samples for the trained SVM classifier.

\begin{tabular}{cccc}
\hline & & \multicolumn{2}{c}{ Actual Class (Cell State) } \\
\hline & & Planktonic & Attached \\
\hline \multirow{2}{*}{$\begin{array}{c}\text { Predicted class } \\
\text { (cell state) }\end{array}$} & Planktonic & 14 & 0 \\
\cline { 2 - 4 } & Attached & 0 & 16 \\
\hline
\end{tabular}

Continuing our analysis, and in order to support our findings and arguments stated earlier, we also conducted a literature search concerning the selected groups of wavenumbers. It is important to mention that the FTIR spectral analysis consists of a quantitative approach to study the metabolic fingerprint and can mainly detect the types of functional groups present in the structure of the molecules. More invasive and time consuming methods are used to identify the exact chemical composition, such as gas chromatography coupled to mass spectrometry. The FTIR spectra analysis, in our case, gave fast real time screening to reveal chemical group compounds and suggest-based on known recoded spectra-the corresponding molecules implicated in biochemical changes that lead to biofilm formation. From this point of view, the FTIR spectra were analyzed to further investigate the compounds, which differentiated the two groups of planktonic and attached cells on the stainless steel surface in order to better understand the mechanism behind this process (Figure 5).

The observed bands at $2960-3005 \mathrm{~cm}^{-1}$ correspond to free amino acids and $\mathrm{CH}$ stretching [44]. The numerous absorption peaks at the $2800-2950 \mathrm{~cm}^{-1}$ region are related to the $\mathrm{CH}_{3}-\mathrm{CH}_{2}-\mathrm{CH}$ strength, containing lipid compounds. More precisely, the stretching vibration of the lipid hydrocarbon tail was observed at 2921 and $2854 \mathrm{~cm}^{-1}\left(\mathrm{CH}_{2}\right)$, as well as at 2960 and $2869 \mathrm{~cm}^{-1}\left(\mathrm{CH}_{3}\right)$ [45]. A shoulder around $2938 \mathrm{~cm}^{-1}$ was also present that was mainly assigned to the $\mathrm{CH}_{2}$ stretching of ergosterol [46]. The peak at $2356 \mathrm{~cm}^{-1}$ was associated with carbon dioxide, while the peak at $1390 \mathrm{~cm}^{-1}$ was associated with the O-H bending of the phenol ring. The 900 to $1250 \mathrm{~cm}^{-1}$ region was typical for polysaccharides due, in part, to $\mathrm{C}-\mathrm{O}-\mathrm{C}$ and $\mathrm{C}-\mathrm{O}$ ring-stretching vibrations, as well as to the $\mathrm{P}=\mathrm{O}$ stretching of phosphodiesters $[47,48]$. More precisely, the peak at $962 \mathrm{~cm}^{-1}$ corresponded to the pyranose ring and the larger region at 1017 to $1045 \mathrm{~cm}^{-1}$, corresponds to the saccharide component ring strength. The component bands that were disclosed mainly concern $\beta$-glucans at $994 \mathrm{~cm}^{-1}(\beta(1-6))$, at $1026 \mathrm{~cm}^{-1}(\beta(1-4))$ and mannans at $1052 \mathrm{~cm}^{-1}$ [49].

\section{Discussion}

B. bruxellensis is a wine spoilage yeast species characterized by a high level of persistence in winery environments due to its biofilm formation capacity on both biotic and abiotic surfaces. The characteristic of this species to contaminate wine cellars and at the same time displaying high resistance to cleaning antimicrobial agents, is a cause of concern for the wine industry $[9,50]$. In our present study we firstly showed that B. bruxellensis strains were discriminated for their capacity to form biofilms on stainless steel surfaces, as has already been observed for other phenotypic traits with oenological interest $[40,51-53]$. The lactic acid bacteria of wine, especially the Oenococus oeni species, have the ability to form biofilms on stainless steel surfaces, while the attached cells contribute to the aromatic profile of the wine [54].

It is necessary for food quality and safety reasons to estimate and assess strain variability, and the related spoilage potential, in order to implement reasonable safety measures [55]. The remarkable adaptation capacity of $B$. bruxellensis is reflected via its genomic plasticity and polymorphisms, which consequently lead to expanded strain variability, while inevitably categorizing the strains vis a vis their spoilage potential [25,56]. Nevertheless, the favorable growth environment of the wine cellar promotes the invasion and surface adhesion of microorganisms [48] and at the same time shapes the genetic partners of the well adapted species $[57,58]$. A similar scenario has been proposed for Saccharomyces cerevisiae, 
where essential genes for adherence (FLO genes) have been maintained in wild lineages, indicating that biofilm formation is important for yeast survival in the wild [59-61].

Interestingly, the biochemical changes that lead to the cells forming biofilms were revealed for the first time by applying FTIR, a non-invasive and easy to use technique. Our innovative approach succeeded in discriminating between the spectra of planktonic vs. attached cells, as well as revealing the metabolic fingerprint implicated in biofilm formation. To date, studies have focused mainly on the proteome of attached cells of bacteria, by revealing protein regulation factors for improved adaptation to hostile conditions $[62,63]$. Respectively, for foodborne pathogens, it has been assumed that the biofilm formation capacity is part of the species dissemination, as the biofilm related genes have been shown to be present in all the tested strains, irrespective of other phenotypes [64].

Unsupervised clustering and supervised classification of the obtained spectra succeed in revealing the two main chemical groups that discriminated the attached vs. the planktonic cells: the polysaccharide and lipid groups. The presence of polysaccharides in the biofilm matrix has been well documented in the literature, especially in the case of bacteria. Polysaccharides are the primary material of the EPS matrix that shape the biofilm structure and also participate in cell attachment to surfaces [12]. In particular, according to our results, the presence of $\beta$-glucan bonding could signify the liberation procedure of the cell wall polysaccharides ( $\beta$ 1-6) or excreted polysaccharides ( $\beta$ 1-4) [65]. Indeed, the presence of $\beta$-glucan has been proven to assist the cell attachment of Botrytis cinerea on grapes [66], while this polymer can modulate cell adhesion to biotic and abiotic surfaces of wine lactic acid bacteria [67]. In the case of lipids, the adhered bacteria can decrease their membrane fluidity by altering the membrane lipid composition and better adapt to environmental conditions. Additionally, it has been documented that biofilms generally possess distinct sterol patterns in diverse phases compared with planktonic cells, and in particular, an increased amount of ergosterol was determined in the early stages of biofilm formation [68].

The excreted molecules, in addition to their role in cell attachment, also serve as signaling molecules to help in the communication between microbial communities. This mechanism, often referred as quorum sensing (QS), is involved in the regulation of biofilm formation, and specifically, in the conformation of the EPS structure [69]. The regulatory system of QS includes intracellular and extracellular signaling that establishes a complicated mechanism that is poorly understood [13]. It is evident that identifying the key compounds of the EPS matrix and unravelling the implicated biosynthetic pathways, will constitute an important step in managing biofilm formation processes. The present work has succeeded in representing an initial approach to study the mechanism behind the biofilm formation capacity of wine spoilage yeast, identifying more feasible a more adapted techniques to prevent future yeast adhesion and contamination during the winemaking process.

\section{Conclusions}

The results obtained from the present study reveal that the biochemical changes that occur during biofilm formation seem to be homogenous for B. bruxellensis, suggesting a common adaptation strategy within the species. Exploiting this outcome, we were able to develop a prediction model for efficiently and reliably assessing the phenotype of planktonic vs. attached cells, for specific strains and cultures. Furthermore, by revealing the metabolites implicated in the adhesion process, this study represents the first approach to better understanding the mechanisms behind yeast persistence in wine production cellars. Our novel developed technique will assist in the future development of preventive strategies against spoilage yeast. 
Supplementary Materials: The following are available online at https:/ /www.mdpi.com/2076-2 607/9/3/587/s1, Figure S1: FTIR spectra: (A) Raw, unprocessed spectra; red line shows the mean planktonic spectrum, while the red shaded area the corresponding standard deviation at each wavenumber across all planktonic samples, the same holds true for the biofilm samples in blue. (B) Truncated at $(880,3100) \mathrm{cm}^{-1}$ and RNV normalized spectra, means and corresponding standard deviations; blue color for the planktonic samples and green for the biofilm ones.

Author Contributions: Conceptualization, G.-J.E.N.; methodology, M.D. and V.K.; formal analysis, M.D. and V.K.; Software, P.T.; resources, S.P. and G.-J.E.N.; data curation, P.T.; writing-original draft preparation, M.D., V.K. and P.T.; writing—review and editing, M.D. and G.-J.E.N.; visualization, P.T. and M.D.; supervision, G.-J.E.N.; project administration, S.P.; funding acquisition, S.P. and G.-J.E.N. All authors have read and agreed to the published version of the manuscript.

Funding: This research was co-financed by the European Regional Development Fund of the European Union and Greek national funds through the Operational Program Competitiveness, Entrepreneurship and Innovation, under the call RESEARCH-CREATE-INNOVATE (project code: T1EDK-04747).

Institutional Review Board Statement: Not applicable.

Informed Consent Statement: Not applicable.

Data Availability Statement: The data presented in this study are available on request from the corresponding author. The data are not publicly available due to fact that explicit information and instructions should be provided.

Conflicts of Interest: The authors declare no conflict of interest. The work described in this manuscript is an original research that has not been published previously, in whole or in part.

\section{References}

1. Agnolucci, M.; Tirelli, A.; Cocolin, L.; Toffanin, A. Brettanomyces Bruxellensis Yeasts: Impact on Wine and Winemaking. World J. Microbiol. Biotechnol. 2017, 33, 180. [CrossRef] [PubMed]

2. Coulon, J.; Perello, M.C.; Lonvaud-Funel, A.; Revel, G.D.; Renouf, V. Brettanomyces Bruxellensis Evolution and Volatile Phenols Production in Red Wines during Storage in Bottles. J. Appl. Microbiol. 2010, 108, 1450-1458. [CrossRef]

3. Dias, L.; Pereira-da-Silva, S.; Tavares, M.; Malfeito-Ferreira, M.; Loureiro, V. Factors Affecting the Production of 4-Ethylphenol by the Yeast Dekkera Bruxellensis in Enological Conditions. Food Microbiol. 2003, 20, 377-384. [CrossRef]

4. Joseph, C.M.; Gorton, L.W.; Ebeler, S.E.; Bisson, L. Production of Volatile Compounds by Wine Strains of Brettanomyces Bruxellensis Grown in the Presence of Different Precursor Substrates. Am. J. Enol. Vitic. 2013, 64, 231-240. [CrossRef]

5. Chatonnet, P.; Dubourdie, D.; Boidron, J.; Pons, M. The Origin of Ethylphenols in Wines. J. Sci. Food Agric. 2006, 60, 165-178. [CrossRef]

6. Serpaggi, V.; Remize, F.; Recorbet, G.; Gaudot-Dumas, E.; Sequeira-Le Grand, A.; Alexandre, H. Characterization of the “Viable but Nonculturable" (VBNC) State in the Wine Spoilage Yeast Brettanomyces. Food Microbiol. 2012, 30, 438-447. [CrossRef]

7. Capozzi, V.; Di Toro, M.R.; Grieco, F.; Michelotti, V.; Salma, M.; Lamontanara, A.; Russo, P.; Orrù, L.; Alexandre, H.; Spano, G. Viable but not Culturable (VBNC) State of Brettanomyces Bruxellensis in Wine: New Insights on Molecular Basis of VBNC Behaviour Using a Transcriptomic Approach. Food Microbiol. 2016, 59, 196-204. [CrossRef]

8. Tristezza, M.; Lourenço, A.; Barata, A.; Brito, L.; Malfeito-Ferreira, M.; Loureiro, V. Susceptibility of Wine Spoilage Yeasts and Bacteria in the Planktonic State and in Biofilms to Disinfectants. Ann. Microbiol. 2010, 60, 549-556. [CrossRef]

9. Lebleux, M.; Abdo, H.; Coelho, C.; Basmaciyan, L.; Albertin, W.; Maupeu, J.; Laurent, J.; Roullier-Gall, C.; Alexandre, H.; Guilloux-Benatier, M.; et al. New Advances on the Brettanomyces Bruxellensis Biofilm Mode of Life. Int. J. Food Microbiol. 2020, 318, 108464. [CrossRef]

10. Dimopoulou, M.; Renault, M.; Dols-Lafargue, M.; Albertin, W.; Herry, J.-M.; Bellon-Fontaine, M.-N.; Masneuf-Pomarede, I. Microbiological, Biochemical, Physicochemical Surface Properties and Biofilm Forming Ability of Brettanomyces Bruxellensis. Ann. Microbiol. 2019, 69, 1217-1225. [CrossRef]

11. Donlan, R.M. Biofilms: Microbial Life on Surfaces. Emerg. Infect. Dis. 2002, 8, 881-890. [CrossRef]

12. Flemming, H.-C.; Wingender, J. The Biofilm Matrix. Nat. Rev. Microbiol. 2010, 8, 623-633. [CrossRef]

13. Monds, R.D.; O'Toole, G.A. The Developmental Model of Microbial Biofilms: Ten Years of a Paradigm up for Review. Trends Microbiol. 2009, 17, 73-87. [CrossRef]

14. Flemming, H.-C.; Wingender, J. Extracellular Polymeric Substances (EPS): Structural, Ecological and Technical Aspects. In Encyclopedia of Environmental Microbiology; American Cancer Society: Atlanta, GA, USA, 2003; ISBN 978-0-471-26339-5.

15. Van de Voort, F.R. Fourier Transform Infrared Spectroscopy Applied to Food Analysis. Food Res. Int. 1992, 25, 397-403. [CrossRef] 
16. Baker, M.J.; Trevisan, J.; Bassan, P.; Bhargava, R.; Butler, H.J.; Dorling, K.M.; Fielden, P.R.; Fogarty, S.W.; Fullwood, N.J.; Heys, K.A.; et al. Using Fourier Transform IR Spectroscopy to Analyze Biological Materials. Nat. Protoc. 2014, 9, 1771-1791. [CrossRef] [PubMed]

17. Wenning, M.; Scherer, S. Identification of Microorganisms by FTIR Spectroscopy: Perspectives and Limitations of the Method. Appl. Microbiol. Biotechnol. 2013, 97, 7111-7120. [CrossRef] [PubMed]

18. Wang, Y.; Zhou, Q.; Li, B.; Liu, B.; Wu, G.; Ibrahim, M.; Xie, G.; Li, H.; Sun, G. Differentiation in MALDI-TOF MS and FTIR Spectra between Two Closely Related Species Acidovorax oryzae and Acidovorax citrulli. BMC Microbiol. 2012, 12, 182. [CrossRef] [PubMed]

19. Gasanov, U.; Hughes, D.; Hansbro, P.M. Methods for the Isolation and Identification of Listeria Spp. and Listeria Monocytogenes: A Review. FEMS Microbiol. Rev. 2005, 29, 851-875. [CrossRef]

20. Papadopoulou, O.; Panagou, E.Z.; Tassou, C.C.; Nychas, G.-J.E. Contribution of Fourier Transform Infrared (FTIR) Spectroscopy Data on the Quantitative Determination of Minced Pork Meat Spoilage. Food Res. Int. 2011, 44, 3264-3271. [CrossRef]

21. Fengou, L.-C.; Lianou, A.; Tsakanikas, P.; Gkana, E.N.; Panagou, E.Z.; Nychas, G.-J.E. Evaluation of Fourier Transform Infrared Spectroscopy and Multispectral Imaging as Means of Estimating the Microbiological Spoilage of Farmed Sea Bream. Food Microbiol. 2019, 79, 27-34. [CrossRef]

22. Tsakanikas, P.; Karnavas, A.; Panagou, E.Z.; Nychas, G.-J. A Machine Learning Workflow for Raw Food Spectroscopic Classification in a Future Industry. Sci. Rep. 2020, 10, 1-11. [CrossRef]

23. Manthou, E.; Lago, S.-L.; Dagres, E.; Lianou, A.; Tsakanikas, P.; Panagou, E.Z.; Anastasiadi, M.; Mohareb, F.; Nychas, G.E. Application of Spectroscopic and Multispectral Imaging Technologies on the Assessment of Ready-to-Eat Pineapple Quality: A Performance Evaluation Study of Machine Learning Models Generated from Two Commercial Data Analytics Tools. Comput. Electron. Agric. 2020, 175, 105529. [CrossRef]

24. Gieroba, B.; Krysa, M.; Wojtowicz, K.; Wiater, A.; Pleszczyńska, M.; Tomczyk, M.; Sroka-Bartnicka, A. The FT-IR and Raman Spectroscopies as Tools for Biofilm Characterization Created by Cariogenic Streptococci. Int. J. Mol. Sci. 2020, 21, 3811. [CrossRef] [PubMed]

25. Avramova, M.; Cibrario, A.; Peltier, E.; Coton, M.; Coton, E.; Schacherer, J.; Spano, G.; Capozzi, V.; Blaiotta, G.; Salin, F. Brettanomyces Bruxellensis Population Survey Reveals a Diploid-Triploid Complex Structured According to Substrate of Isolation and Geographical Distribution. Sci. Rep. 2018, 8, 4136. [CrossRef] [PubMed]

26. Albertin, W.; Panfili, A.; Miot-Sertier, C.; Goulielmakis, A.; Delcamp, A.; Salin, F.; Lonvaud-Funel, A.; Curtin, C.; MasneufPomarede, I. Development of Microsatellite Markers for the Rapid and Reliable Genotyping of Brettanomyces Bruxellensis at Strain Level. Food Microbiol. 2014, 42, 188-195. [CrossRef] [PubMed]

27. Geurts, P.; Ernst, D.; Wehenkel, L. Extremely Randomized Trees. Mach. Learn. 2006, 63, 3-42. [CrossRef]

28. Jolliffe, I.T. Principal Component Analysis, 2nd ed.; Springer: New York, NY, USA, 2002; ISBN 978-0-387-95442-4.

29. McLachlan, G.J.; Ng, S.K.; Peel, D. On Clustering by Mixture Models. In Exploratory Data Analysis in Empirical Research; Schwaiger, M., Opitz, O., Eds.; Springer: Berlin/Heidelberg, Germany, 2003; pp. 141-148. ISBN 978-3-540-44183-0.

30. Cortes, C.; Vapnik, V. Support-Vector Networks. Mach. Learn. 1995, 20, 273-297. [CrossRef]

31. Guo, Q.; Wu, W.; Massart, D.L. The Robust Normal Variate Transform for Pattern Recognition with Near-Infrared Data. Anal. Chim. Acta 1999, 382, 87-103. [CrossRef]

32. Barnes, R.J.; Dhanoa, M.S.; Lister, S.J. Standard Normal Variate Transformation and De-Trending of Near-Infrared Diffuse Reflectance Spectra. Appl. Spectrosc. 2016, 43, 772-777. [CrossRef]

33. Hoaglin, D.C.; Mosteller, F.; Tukey, J.W. Understanding Robust and Exploratory Data Analysis, 1st ed.; John Wiley \& Sons: Hoboken, NJ, USA, 2000; ISBN 978-0-471-38491-5.

34. Estelles-Lopez, L.; Ropodi, A.; Pavlidis, D.; Fotopoulou, J.; Gkousari, C.; Peyrodie, A.; Panagou, E.; Nychas, G.-J.; Mohareb, F. An Automated Ranking Platform for Machine Learning Regression Models for Meat Spoilage Prediction Using Multi-Spectral Imaging and Metabolic Profiling. Food Res. Int. 2017, 99, 206-215. [CrossRef]

35. Ropodi, A.I.; Panagou, E.Z.; Nychas, G.-J.E. Data Mining Derived from Food Analyses Using Non-Invasive/Non-Destructive Analytical Techniques, Determination of Food Authenticity, Quality \& Safety in Tandem with Computer Science Disciplines. Trends Food Sci. Technol. 2016, 50, 11-25. [CrossRef]

36. Tsakanikas, P.; Fengou, L.-C.; Manthou, E.; Lianou, A.; Panagou, E.Z.; Nychas, G.-J.E. A Unified Spectra Analysis Workflow for the Assessment of Microbial Contamination of Ready to Eat Green Salads: Comparative Study and Application of Non-Invasive Sensors. Comput. Electron. Agric. 2018, 155, 212-219. [CrossRef]

37. Hearst, M.A.; Dumais, S.T.; Osuna, E.; Platt, J.; Scholkopf, B. Support Vector Machines. IEEE Intell. Syst. Appl. 1998, 13, 18-28. [CrossRef]

38. Pedregosa, F.; Varoquaux, G.; Gramfort, A.; Michel, V.; Thirion, B.; Grisel, O.; Blondel, M.; Prettenhofer, P.; Weiss, R.; Dubourg, V.; et al. Scikit-Learn: Machine Learning in Python. J. Mach. Learn. Res. 2011, 12, 2825-2830.

39. Joseph, L.; Kumar, G.; Su, E.; Bisson, L. Adhesion and biofilm production by wine isolates of Brettanomyces bruxellensis. Am. J. Enol. Vitic. 2007, 58, 373-378.

40. Dimopoulou, M.; Hatzikamari, M.; Masneuf-Pomarede, I.; Albertin, W. Sulfur Dioxide Response of Brettanomyces bruxellensis Strains Isolated from Greek Wine. Food Microbiol. 2019, 78, 155-163. [CrossRef]

41. Avramova, M.; Vallet-Courbin, A.; Maupeu, J.; Masneuf-Pomarède, I.; Albertin, W. Molecular Diagnosis of Brettanomyces Bruxellensi's Sulfur Dioxide Sensitivity through Genotype Specific Method. Front. Microbiol. 2018, 9, 1260. [CrossRef] 
42. López, D.; Vlamakis, H.; Kolter, R. Biofilms. Cold Spring Harb. Perspect. Biol. 2010, 2, a000398. [CrossRef]

43. Aggarwal, S.; Stewart, P.S.; Hozalski, R.M. Biofilm Cohesive Strength as a Basis for Biofilm Recalcitrance: Are Bacterial Biofilms Overdesigned? Microbiol. Insights 2016, 8, 29-32. [CrossRef]

44. Hall-Stoodley, L.; Costerton, J.W.; Stoodley, P. Bacterial Biofilms: From the Natural Environment to Infectious Diseases. Nat. Rev. Microbiol. 2004, 2, 95-108. [CrossRef]

45. Socrates, G. Infrared and Raman Characteristic Group Frequencies: Tables and Charts; John Wiley \& Sons: Hoboken, NJ, USA, 2004; ISBN 978-0-470-09307-8.

46. Arrondo, J.L.; Goñi, F.M. Infrared Studies of Protein-Induced Perturbation of Lipids in Lipoproteins and Membranes. Chem. Phys. Lipids 1998, 96, 53-68. [CrossRef]

47. Berterame, N.M.; Porro, D.; Ami, D.; Branduardi, P. Protein Aggregation and Membrane Lipid Modifications under Lactic Acid Stress in Wild Type and OPI1 Deleted Saccharomyces Cerevisiae Strains. Microb. Cell Factories 2016, 15, 39. [CrossRef]

48. Lembre, P.; Lorentz, C.; Martino, P.D. Exopolysaccharides of the Biofilm Matrix: A Complex Biophysical World. Complex World Polysacch. 2012, 371-392. [CrossRef]

49. Galichet, A.; Sockalingum, G.D.; Belarbi, A.; Manfait, M. FTIR Spectroscopic Analysis of Saccharomyces Cerevisiae Cell Walls: Study of an Anomalous Strain Exhibiting a Pink-Colored Cell Phenotype. FEMS Microbiol. Lett. 2001, 197, 179-186. [CrossRef]

50. Blanco, P.; Orriols, I.; Losada, A. Survival of Commercial Yeasts in the Winery Environment and Their Prevalence during Spontaneous Fermentations. J. Ind. Microbiol. Biotechnol. 2011, 38, 235-239. [CrossRef]

51. Agnolucci, M.; Vigentini, I.; Capurso, G.; Merico, A.; Tirelli, A.; Compagno, C.; Foschino, R.; Nuti, M. Genetic Diversity and Physiological Traits of Brettanomyces Bruxellensis Strains Isolated from Tuscan Sangiovese Wines. Int. J. Food Microbiol. 2009, 130, 238-244. [CrossRef]

52. Longin, C.; Degueurce, C.; Julliat, F.; Guilloux-Benatier, M.; Rousseaux, S.; Alexandre, H. Efficiency of Population-Dependent Sulfite against Brettanomyces bruxellensis in Red Wine. Food Res. Int. 2016, 89, 620-630. [CrossRef]

53. Crauwels, S.; Van Opstaele, F.; Jaskula-Goiris, B.; Steensels, J.; Verreth, C.; Bosmans, L.; Paulussen, C.; Herrera-Malaver, B.; De Jonge, R.; De Clippeleer, J.; et al. Fermentation Assays Reveal Differences in Sugar and (off-) Flavor Metabolism across Different Brettanomyces bruxellensis Strains. FEMS Yeast Res. 2017, 17. [CrossRef]

54. Bastard, A.; Coelho, C.; Briandet, R.; Canette, A.; Gougeon, R.; Alexandre, H.; Guzzo, J.; Weidmann, S. Effect of Biofilm Formation by Oenococcus oeni on Malolactic Fermentation and the Release of Aromatic Compounds in Wine. Front. Microbiol. $2016,7,613$. [CrossRef]

55. Cibrario, A.; Miot-Sertier, C.; Paulin, M.; Bullier, B.; Riquier, L.; Perello, M.-C.; De Revel, G.; Albertin, W.; Masneuf-Pomarède, I.; Ballestra, P.; et al. Brettanomyces bruxellensis Phenotypic Diversity, Tolerance to Wine Stress and Wine Spoilage Ability. Food Microbiol. 2020, 87, 103379. [CrossRef]

56. Lianou, A.; Nychas, G.-J.E.; Koutsoumanis, K.P. Strain Variability in Biofilm Formation: A Food Safety and Quality Perspective. Food Res. Int. 2020, 137, 109424. [CrossRef]

57. Romano, A.; Perello, M.C.; Revel, G.D.; Lonvaud-Funel, A. Growth and Volatile Compound Production by Brettanomyces/Dekkera Bruxellensis in Red Wine. J. Appl. Microbiol. 2008, 104, 1577-1585. [CrossRef]

58. Cibrario, A.; Avramova, M.; Dimopoulou, M.; Magani, M.; Miot-Sertier, C.; Mas, A.; Portillo, M.C.; Ballestra, P.; Albertin, W.; Masneuf-Pomarede, I.; et al. Brettanomyces bruxellensis Wine Isolates Show High Geographical Dispersal and Long Persistence in Cellars. PLoS ONE 2019, 14, e0222749. [CrossRef]

59. Guo, B.; Styles, C.A.; Feng, Q.; Fink, G.R. A Saccharomyces Gene Family Involved in Invasive Growth, Cell-Cell Adhesion, and Mating. Proc. Natl. Acad. Sci. USA 2000, 97, 12158-12163. [CrossRef]

60. Fidalgo, M.; Barrales, R.R.; Ibeas, J.I.; Jimenez, J. Adaptive Evolution by Mutations in the FLO11 Gene. Proc. Natl. Acad. Sci. USA 2006, 103, 11228-11233. [CrossRef] [PubMed]

61. Legras, J.-L.; Galeote, V.; Bigey, F.; Camarasa, C.; Marsit, S.; Nidelet, T.; Sanchez, I.; Couloux, A.; Guy, J.; Franco-Duarte, R.; et al. Adaptation of S. Cerevisiae to Fermented Food Environments Reveals Remarkable Genome Plasticity and the Footprints of Domestication. Mol. Biol. Evol. 2018, 35, 1712-1727. [CrossRef]

62. Giaouris, E.; Samoilis, G.; Chorianopoulos, N.; Ercolini, D.; Nychas, G.-J. Differential Protein Expression Patterns between Planktonic and Biofilm Cells of Salmonella Enterica Serovar Enteritidis PT4 on Stainless Steel Surface. Int. J. Food Microbiol. 2013, 162, 105-113. [CrossRef] [PubMed]

63. Soares, A.; Gomes, L.C.; Mergulhão, F.J. Comparing the Recombinant Protein Production Potential of Planktonic and Biofilm Cells. Microorganisms 2018, 6, 48. [CrossRef] [PubMed]

64. Mizan, M.F.R.; Jahid, I.K.; Kim, M.; Lee, K.-H.; Kim, T.J.; Ha, S.-D. Variability in Biofilm Formation Correlates with Hydrophobicity and Quorum Sensing among Vibrio Parahaemolyticus Isolates from Food Contact Surfaces and the Distribution of the Genes Involved in Biofilm Formation. Biofouling 2016, 32, 497-509. [CrossRef] [PubMed]

65. Kollár, R.; Reinhold, B.B.; Petráková, E.; Yeh, H.J.C.; Ashwell, G.; Drgonová, J.; Kapteyn, J.C.; Klis, F.M.; Cabib, E. Architecture of the yeast cell wall $\beta(1 \rightarrow 6)$-glucan interconnects mannoprotein, $\beta(1 \rightarrow 3)$-glucan, and chitin. J. Biol. Chem. 1997, 272, 17762-17775. [CrossRef]

66. Dimopoulou, M.; Lonvaud-Funel, A.; Dols-Lafargue, M. Polysaccharide Production by Grapes Must and Wine Microorganisms. In Biology of Microorganisms on Grapes, in Must and in Wine; König, H., Unden, G., Fröhlich, J., Eds.; Springer: Cham, Switzerland, 2017; pp. 293-314. ISBN 978-3-319-60021-5. 
67. Blättel, V.; Larisika, M.; Pfeiffer, P.; Nowak, C.; Eich, A.; Eckelt, J.; König, H. Beta-1,3-Glucanase from Delftia Tsuruhatensis Strain MV01 and Its Potential Application in Vinification. Appl. Environ. Microbiol. 2011, 77, 983-990. [CrossRef] [PubMed]

68. Lv, Q.; Yan, L.; Jiang, Y. The Synthesis, Regulation, and Functions of Sterols in Candida Albicans: Well-Known but Still Lots to Learn. Virulence 2016, 7, 649-659. [CrossRef] [PubMed]

69. Ng, W.-L.; Bassler, B.L. Bacterial Quorum-Sensing Network Architectures. Ann. Rev. Genet. 2009, 43, 197-222. [CrossRef] [PubMed] 